\title{
Synthetic hydrology and climate change scenarios to improve multi-purpose complex water resource systems management. The Lake Ontario - St Lawrence River Study of the International Canada and US Joint Commission
}

\author{
L. Fagherazzi ${ }^{1}$, D. Fay $^{2}$ \& J. Salas ${ }^{3}$ \\ ${ }^{I}$ Plan pluriannuel et systèmes hydriques, Hydro-Québec, Canada \\ ${ }^{2}$ Great Lakes - St. Lawrence Regulation Office, Cornwall, Canada \\ ${ }^{3}$ Department of Civil Engineering, Colorado State University, USA
}

\begin{abstract}
The hydrological data used in the design, planning and operational studies of water resource schemes are often limited to historical records, which are usually short, incomplete, sparsely distributed in space, and poorly synchronized. Moreover, a particular sequence of flow observations rarely reoccurs in identical form in a future period. If important characteristics of the historical series such as annual sequences of low and high flows are poorly modeled, design and/or planning shortcomings may then result, because their effects were underestimated. To better grasp drought and flood variability, the Lake Ontario St. Lawrence River Study used both historical and synthetic hydrological scenarios. A set of stochastic hydrological Net Basin Supplies series for the Great Lakes, and local inflows of the St Lawrence River's major tributaries upstream from Trois-Rivieres sequences was developed, based on the statistical properties of the historical series. The set constitutes a large number of potential hydrological scenarios that could occur due to the observed natural variation in climate. The simulated series were then used, along with the observed 1900-2000 data, to design and evaluate the adequacy of newly proposed Lake Ontario multiobjective management strategies. In addition, four hydrologic scenarios incorporating climate change fields on seven climate variables were developed for the Great Lakes and Ottawa River. Scenarios from General Circulation Model (GCM) output changes, covering the range of climate change variability for the future 30-year period 2040-2069, were used to test the robustness of the management strategies under possible future climates. This paper summarizes the special hydrological characteristics of the Great Lakes - St. Lawrence River System, the major modeling hypothesis and retained strategies used to prepare a stochastic generation model, and the preparation of climate change scenarios for a major tributary, the Ottawa River basin. It also illustrates their use in evaluating Lake Ontario multiobjective management strategies.
\end{abstract}

Keywords: stochastic generation model, shifting mean and ARMA process, climate change scenarios, Lake Ontario regulation plans. 


\section{Introduction}

The Great Lakes - St Lawrence River system is a complex lake-river system, having large amounts of over-year storage, characterized by particular spatial and temporal properties of inflows series. Figure 1 presents the basins and subbasins of the system, covering an area of $1021000 \mathrm{~km}^{2}$. The orange trace outlines the Great Lakes system, the green the Ottawa River system and the red the Lower St Lawrence River tributaries that were considered in the study.

As explained in $[4,6,7]$, since October 1963 Lake Ontario outflows have been regulated according to the rules of Plan1958-D (International St. Lawrence River Board of Control. 1963), which was developed and tested using the historical 1860-1954 Lake Ontario total water supplies. Since regulation began, more extreme dry and wet supply scenarios have been observed on the lower lakes, resulting in Lake Ontario water levels and flows outside the range of the existing International Joint Commission criteria.

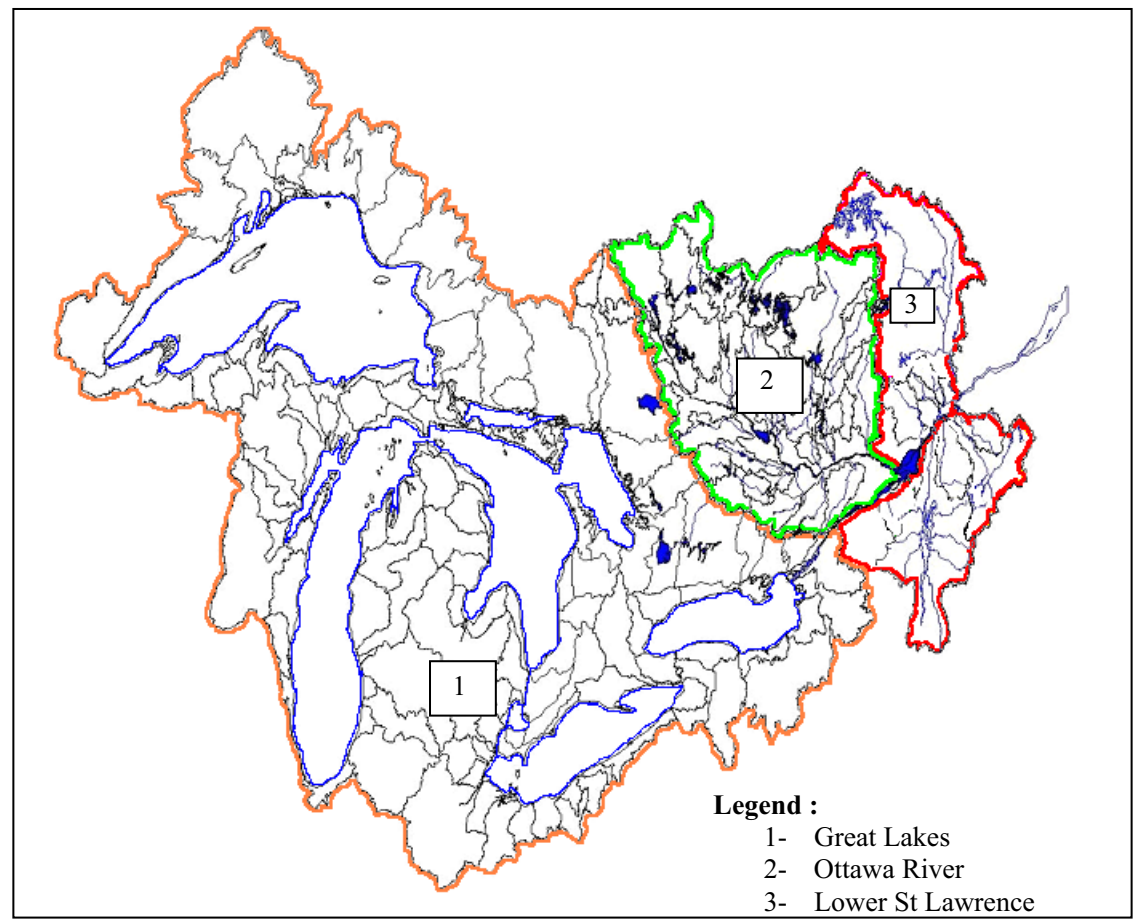

Figure 1: Chart of the Great Lakes - St. Lawrence River tributaries.

To improve the Lake Ontario multiobjective management strategies and to better understand the variability and range of plan performance, an innovative approach was used by the Lake Ontario-St Lawrence River Study (LOSLRS) of 
the International Joint Commission. As explained in [2], a joint effort involving the participation of an international group of experts has been undertaken to characterize the statistical properties of the hydrological system, formulate an adequate stochastic model, and simulate a sample set of 50000 years of synthetic Net Basin Supplies (NBS) for the Great Lakes and local inflows of the St Lawrence River's major tributaries upstream from Trois-Rivieres. Of particular interest to the planners was the reproduction of the temporal variability at each site (high and low flows), at each time step (annual, quarter-monthly), and the spatial characteristics (cross-correlation structure) between the Great Lakes and the Ottawa River System, the most important St Lawrence River tributary located immediately downstream.

To consider the impacts of climate change on Lake Ontario total supplies and the Ottawa River outflows, four hydrological scenarios exhibiting a wide range of plausible GCM climate changes on several climate variables, were prepared for the LOSLRS study region [2, 4, 8]. Adjusted historical meteorology (Method of Deltas) were then used to simulate four hydrologic sequences reflecting the climate change impacts over the Great Lakes and St Lawrence River tributaries, used to test the robustness of newly proposed Lake Ontario management strategies.

The present document is organized in four sections, as follows:

1. Inflow Data Analysis, presenting special characteristics of Great Lakes NBS and St Lawrence tributaries' flows at annual level.

2. Stochastic Model Formulation, including selection criteria (temporal and spatial characteristics of the inflows to be considered explicitly in the modelling approach), modelling strategies (annual, annualmonthly), and selected model results, comparing the statistical characteristics of historical and synthetic NBS series at annual level.

3. Climate Change Hydrological Scenarios, describing preparation of hydrological sequences for the Ottawa River basin.

4. Simulation of synthetic and climate change hydrological series using Lake Ontario's "Plan 1958-D with deviations" and analysis of resulting levels statistics.

\section{Special characteristics of the hydrological data}

\subsection{Great Lakes annual inflows characteristics}

Water inflows for each lake are presented as Net Basin Supplies (NBS), representing the net result of runoff from the tributaries and aquifers draining into the lake, precipitation directly over the lake, and evaporation from the lake $[3,5]$. The analysed hydrological set starts in January 1900 and finishes in December 2000.

The stochastic spatial and temporal characteristics of the Great Lakes NBS are very complex. Figure 2 shows the time plot of the four Great Lakes annual NBS values along with their corresponding mean. Lakes Erie and Ontario time 
plots, at the bottom, suggest the presence of local non-stationarities in their annual NBS. Dry and wet sequences seem to have occurred simultaneously on both lakes, like the dry spells of the 1930s and mid-1960s, and the wet sequences of 1927-1931 and 1970s and 1980s. Very similar behaviour was found in the precipitation series (not shown).
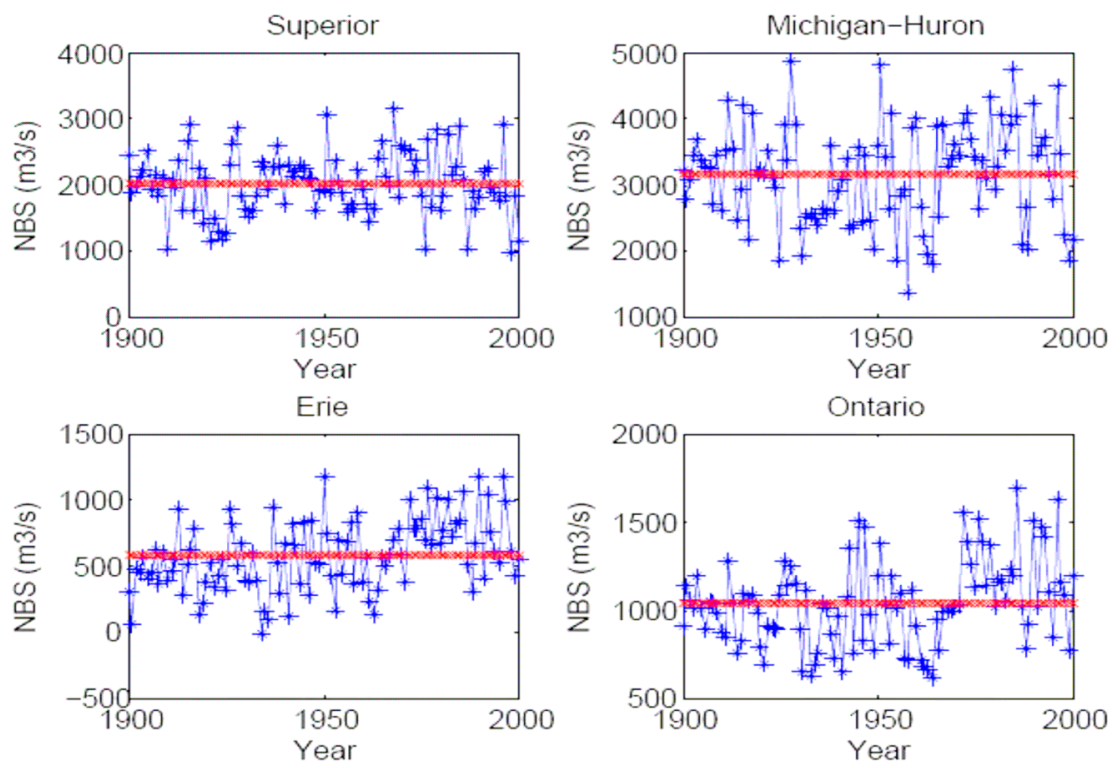

Figure 2: $\quad$ Time plots for the Great Lakes.

These local non-stationarities are definitively not present in the annual NBS of Lake Superior. Annual data of Lake Michigan-Huron, on the upper right part, seems to present also the dry spells of the 1930s and 1960s, and the wet sequence of the 1970s, but not as intensely as the Lower Lakes. For lakes Superior and Michigan-Huron, the lag-1 correlation coefficients are low and non significant at a 5\% level of significance, and the general shape of the autocorrelation function shows a smooth decay to lag-5 [3]. On the contrary, the lag-1 to lag-4 coefficients for Lake Ontario and the lag-1 to lag-5 coefficients for lake Erie are still low but significant at the $5 \%$ level of significance. Their serial autocorrelation plot shows a slow decay for many lags.

Many techniques were applied to the Great Lakes data series (NBS and precipitation) for detecting and testing the statistical significance of these special temporal characteristics, like Lee and Heguinian Bayesian statistics, wavelets analysis, and two-state multivariate Hidden Markov procedures [3]. The following can be concluded:

- It seems that there are no significant changes in the mean of annual NBS series for Lake Superior. 
- Annual NBS series for Lakes Michigan-Huron, Erie and Ontario seem to have exhibited multiple shifts in the mean. The most important change is positive, occurs around 1970 on Lakes Erie and Ontario and spans many years. Moreover, annual serial correlations for the Lower Lakes are low but significant for many lags.

- Annual cross-correlations decrease with the distance between lakes. Lake Michigan-Huron, Erie and Ontario cross-correlations are significant, varying between 0.5 and 0.7 .

\subsection{Ottawa River and other Lower St Lawrence River tributaries spatial characteristics}

The Ottawa River system was divided into 28 sub-basins. The hydrological series were parsed to form a concomitant period starting in January 1969 and ending in December 2000, with 32 years of recorded data. Most of the sites show no significant annual serial correlation. However, three sub-basins located in the southern portion show local non-stationarities, characterised by significant serial correlation for several lags, high cross-correlation with Lake Ontario NBS, and somewhat lower correlation with Lake Erie NBS.

Four tributaries to the lower St Lawrence River, other than the Ottawa River, were selected to represent the hydrological characteristics of the intermediate basin between Cornwall and Trois-Rivieres. Their annual lag-1 serial correlations are non significant.

\section{Stochastic model formulation}

To evaluate the adequacy of Lake Ontario management strategies on the overall GLSLR system, it is necessary to generate concurrent NBS and flows at all 36 sites. Because the number of years of available time series is short, and the number of sites is too high to estimate parsimoniously the parameters of the stochastic generation models using all data at once, it was necessary to reduce the number of sites. The alternative of aggregating spatially the available data was chosen, in order to create homogeneous groups according some representative variables. Consequently, the whole GLSLR system was grouped into 10 regions: the four Great Lakes, five Ottawa regions and the Lower St Lawrence River tributaries region.

The system's special stochastic characteristics oriented the choice to a multivariate contemporaneous mix of Shifting Mean and ARMA process, for annual modeling of series with shifts in the mean, and regular stationary ARMA processes [3, 10-12]. The annual model characterizing the 10 regions was coupled with a disaggregation model for the annual to monthly disaggregation of flows in time and space ( 36 sites). To reduce the size of the disaggregation model, many strategies of decoupling the problem in stages were tested to minimize the number of parameters and maximise the explicitly preserved statistics. Finally, a temporal-spatial strategy using the Stedinger, Pei and Cohn disaggregation procedure for the temporal disaggregation and the Mejia and 
Rouselle model for the spatial disaggregation was selected. This choice enabled use of all data. The Stedinger temporal disaggregation model, being contemporaneous, produces the best results with the different sample lengths.

\subsection{Routed series}

A generated set of 10000 years of NBS series for Lakes Superior, Michigan Huron and Erie using the selected modeling strategy was routed with the Coordinated Great Lakes Regulation and Routing Model [5], along with initial lake levels, and series of channel ice roughness data and diversions. The final output is the routed monthly or quarter-monthly series of outflows and levels for Lake Erie.

Lake Erie simulated outflows and Lake Ontario NBS were then combined and routed using the Lake Ontario pre-project outlet conditions [1]. This set of Lake Ontario outflows and levels values constitutes a reference basis for comparison of the simulated outflows using historical NBS series and routed outflows and levels from the generated NBS series.

Figures 3 and 4 show Empirical Frequency Plots of 100 samples of 100 years of the routed annual average outflows calculated from routed generated and historical data. Figure 3 illustrates an enhanced view of the upper tail of Lake Erie's average annual outflows. The red curve illustrates the sorted observed annual outflows while the blue curves show routed synthetic outflows series. Lake Erie results summarize the characteristics of the Upper Lakes. The graph shows a good agreement with the historical series and a lot of variability of the samples around the observed series. Figure 4 shows the upper tail of routed annual average outflows at Lake Ontario, calculated from quarter-monthly data. The results are presented in tens of $\mathrm{m}^{3} / \mathrm{s}\left(* 10 \mathrm{~m}^{3} / \mathrm{s}\right)$. Although all frequencies were reproduced, there is less uniformity in the dispersion in the high tail.

Once the statistical characteristics of the generated series were assessed, four 101-year long Lake Ontario net total supply (Lake Erie outflow plus NBS) series were extracted to develop and test newly proposed Lake Ontario management strategies under "different than the observed water supply conditions". Those sequences exhibit the lowest and highest 5-year moving average supply, the largest range from wet and dry supplies, the longest Lake Ontario drought, and a sequence closer to the average but with a different annual pattern than the observed one [5, 7]. The full 50000-year stochastic series were used to assess the variability and range of the management strategies performance. Some descriptive statistics using "Plan 1958-D with deviations" will be presented in the last section.

\section{Climate change scenarios}

To consider the possible impacts of climate change on inflows to the different major basins of the Lake Ontario - St Lawrence River system, and resulting water levels and outflows, four hydrological scenarios were prepared with meteorological outputs from individual General Circulation Model GCM 


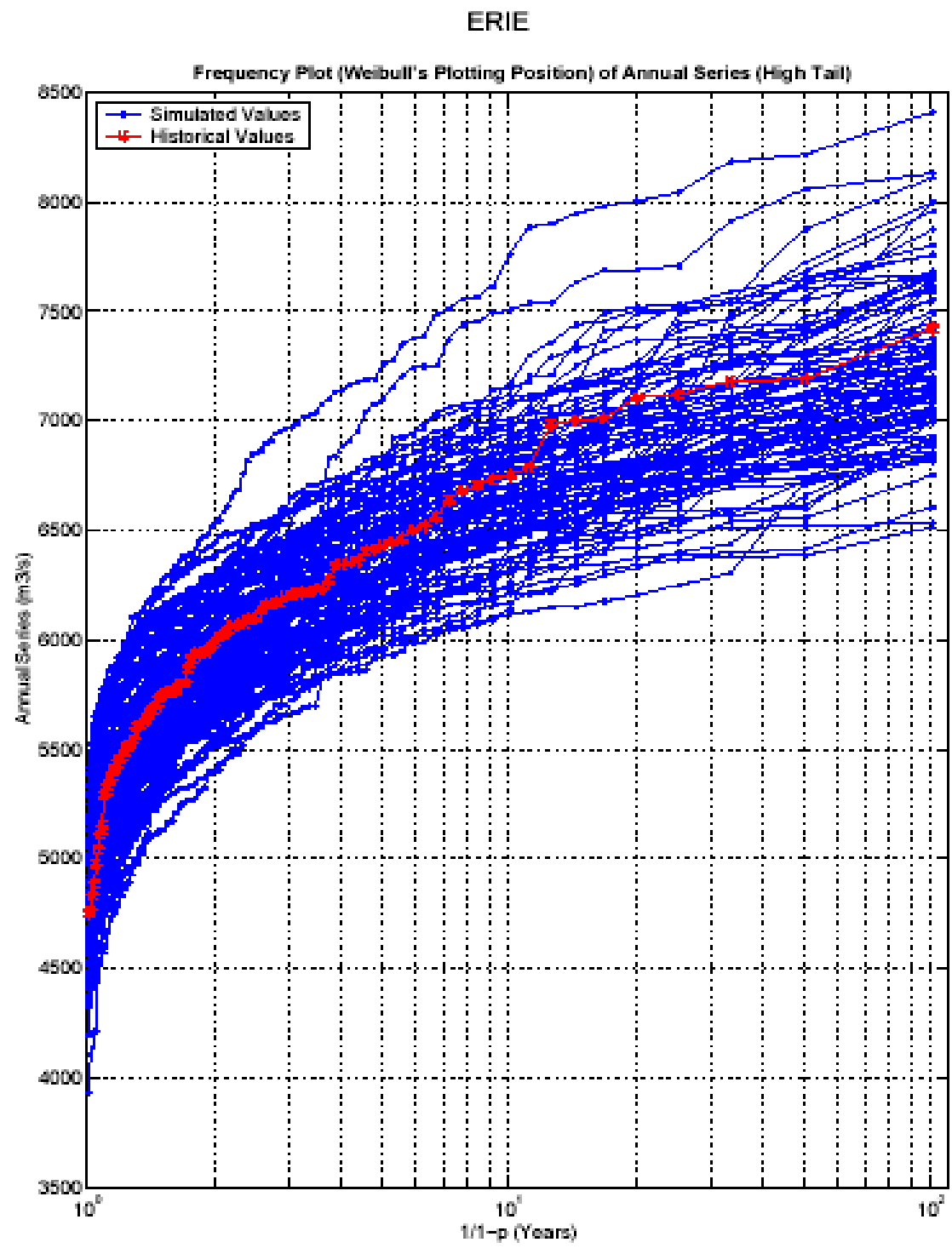

Figure 3: Empirical frequency plots of 100 samples of 100 years simulated annual average outflows vs historical outflows - Lake Erie (calculated from monthly values). 


\section{Ontario}

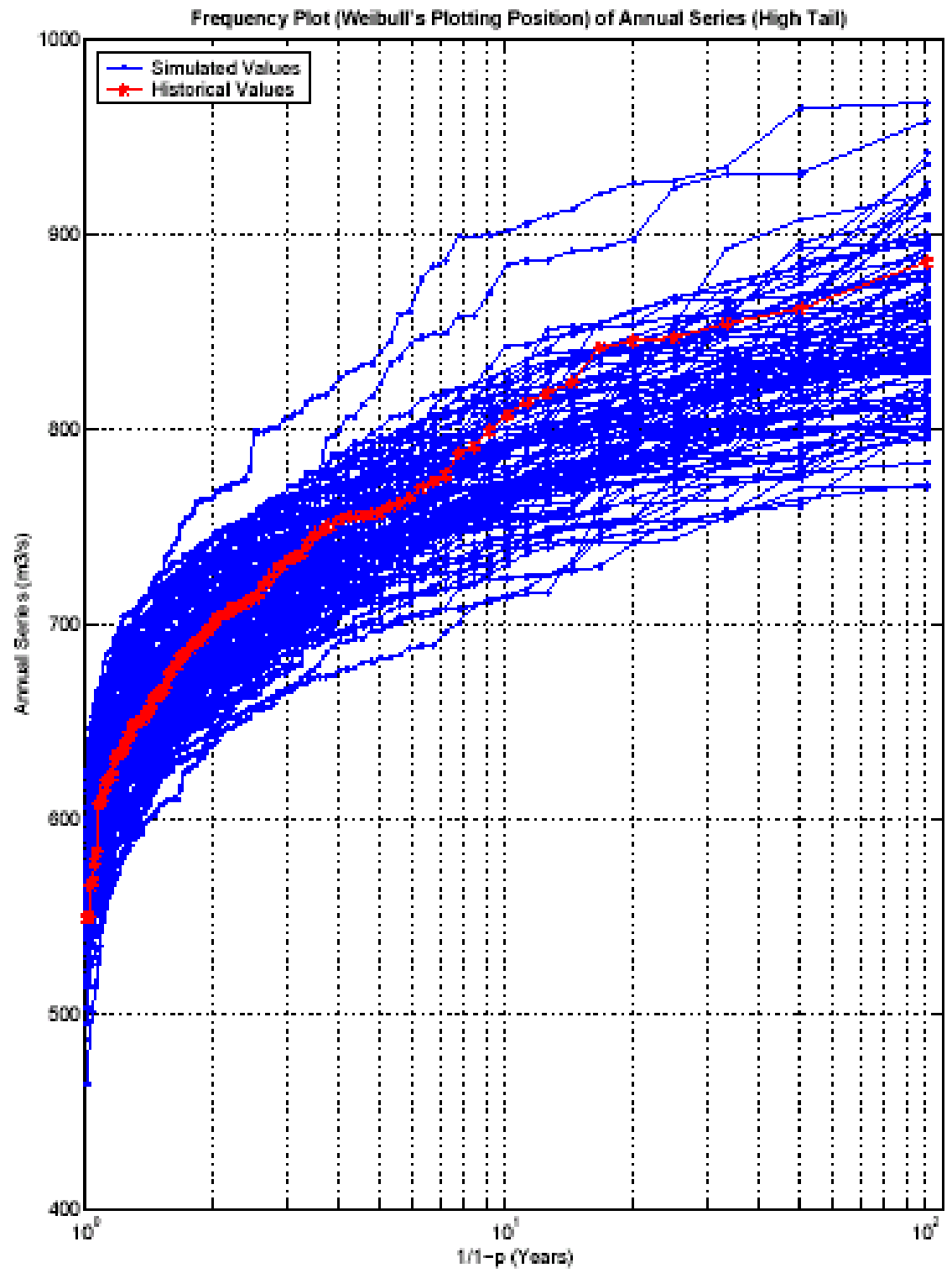

Figure 4: Empirical frequency plots of 100 samples of 100 years simulated annual average outflows vs historical outflows - Lake Ontario ((calculated from quarter-monthly values). 
simulation results. The Hydrology and Hydraulics Technical Working Group of the LOSLR Study selected four climate scenarios exhibiting 1) most warming and wettest, 2) most warming and driest, 3) least warming and wettest, and 4) least warming and driest conditions, with the goal of "boxing the uncertainty" [8]. Downscaling of the GCM scenarios was limited to interpolation of the GCM grids.

The Great Lakes Environmental Research Laboratory GLERL (Ann Arbor, US) acquired the identified GCM climate change scenarios and supplied results to hydrologic modellers: monthly GCM output changes between the baseline period and the future 30-year period (2040-2069). GLERL adjusted historical meteorology data for the Great Lakes basin (spanning the 1950-1999 period) with the GCM climate changes, and used hydrological runoff and lake model of the Great Lakes to simulate NBS scenarios for the base case, that is local inflows series resulting from observed climatology, and each climate change scenario [2, 5]. The Great Lakes NBS series for the base case and each of the four changed climate scenarios were then routed with the Coordinated Great Lakes Regulation and Routing model to prepare five sets of Lake Erie outflows and net total supply series for Lake Ontario. Hydro Quebec and the Quebec Ministry of Environment, from Canada, prepared the base case and four climate change sets of intermediate flows to each of the 40 Ottawa River designated sub-basins. The observed meteorological data were obtained for the 1962-1990 period. The five sets of sub-basin inflows were then routed to the river mouth, at Carillon, using the MENVIQ routing model and adequate management rules.

The following color map, Figure 5, shows the spatial variation of the mean annual runoff for the most warming and driest climate scenario. The map shows mean annual values by surface unit, for resulting inflows of the overall Great Lakes and Ottawa River System. In spite of different hydrological and routing models used for the Great Lakes and Ottawa River sub-basins, the color maps shows overall harmonious behaviour of the two systems. The transition at the frontier of the two systems is very smooth. Reference [2] illustrates Lake Ontario net total supply annual and quarter-monthly characteristics for the base case and the climate change scenarios. The following section describes more detailed results of the climate change analysis on the Ottawa River system.

\subsection{The Ottawa River system}

The analysis of the climate variables shows that the resulting annual mean total precipitation (liquid rain plus snow) for the four climate change scenarios were higher than the observed record. Because the annual maximum and minimum temperatures also increase, the evapotranspiration is higher for all scenarios. The net impact on inflows is generally an increase in the Ottawa River system. For one scenario (warm/dry), the annual mean corresponding inflow is lower than the base case.

Monthly histograms of differences between the climate change scenarios and the base case show increasing rainfall in winter months for all scenarios, lower snowfall amounts in January, February, March and April for the one of the GCM scenarios, and an overall increase of total precipitation. 


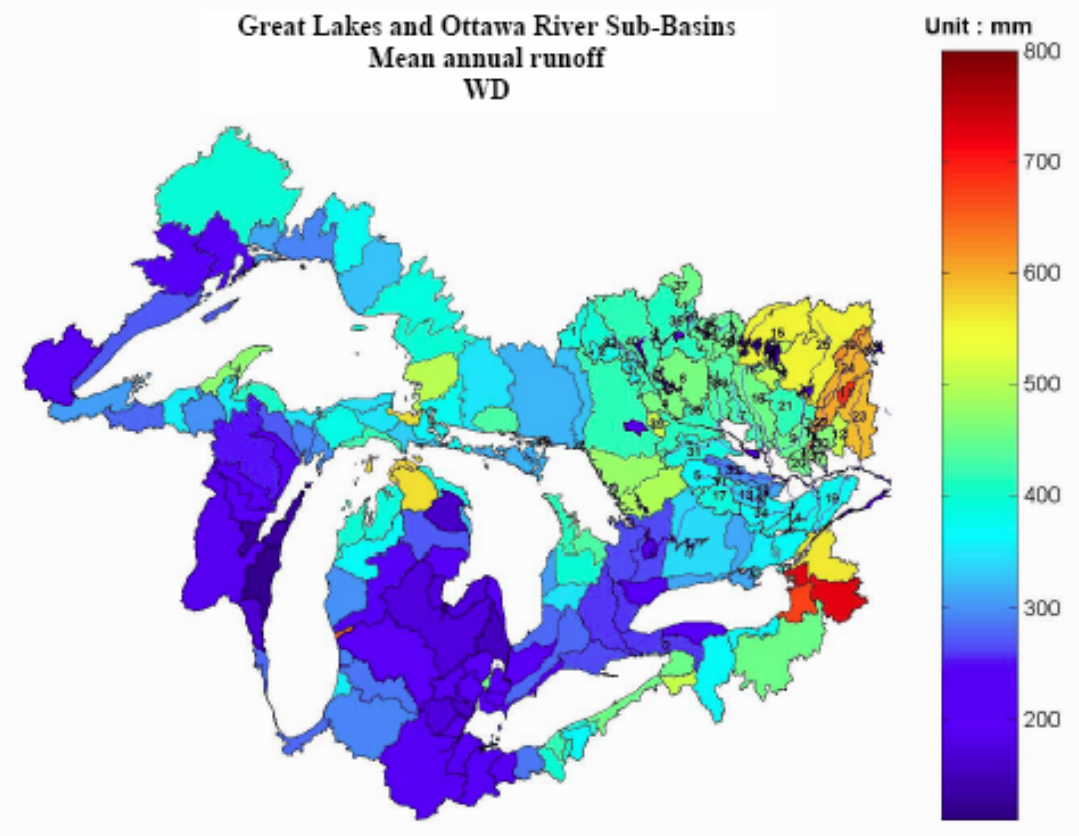

Figure 5: Great Lakes and Ottawa River spatial variation of the mean annual runoff for the most warming and driest climate scenario.

The routing of the Climate Change hydrological scenarios showed that MENVIQ Routing Model management rules based on the historical flows were not able to respect the actual storage volume and reservoir water level requirements. The drift to early spring floods and more flow peaks during the winter months that characterize the climate change inflows hydrographs produce higher discharges in late winter months than the outflows set according to the existing management rules, which specify that reservoir levels should be emptied in preparation for the spring flood. Consequently, the reservoir storage could not be adequately filled with the spring floods, and the expected reservoir water levels during the summer season were hard to reach.

Changes to the reservoir management rules were necessary, but it was impossible to anticipate the management outflow and level constraints required to prepare an optimal set of management rules for each climate change scenario. Finally, it was decided to develop a general adjustment to existing management rules for all scenarios, respecting the actual set of level and outflow constraints of the system. It was established that the spring flood shifts by about -30 days on average, for the four $\mathrm{CC}$ scenarios and all sub-basins. The management rules were consequently modified to better respect the operational constraints by shifting constraints dates by 30 days. 


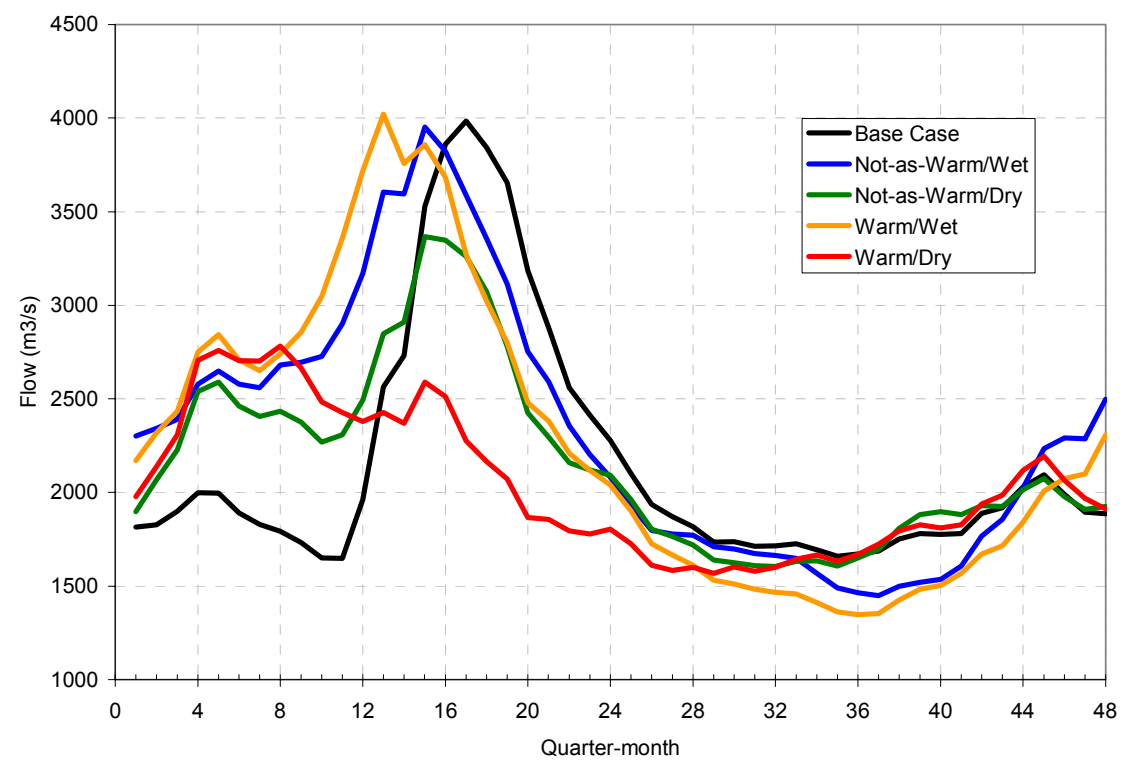

Figure 6: Comparison of quarter-monthly outflows Averages at Carillon, the outlet of the Ottawa River system.

Figure 6 shows the routed quarter-monthly mean outflow hydrographs for the base case and each of the four CC scenarios at Carillon. The simulated hydrographs show a similar increase of the average mean outflow during January and February for all four scenarios, a drift to earlier spring floods (resulting from higher mean total precipitation and annual minimum temperature increase, producing increasing rainfall in winter months), but major differences between the CC scenarios during March and April.

\section{Lake Ontario management strategies}

The LOSLR Study has introduced a new planning development vision combining scientific work, constraints and preferences of the affected interests, and public input in an interactive analytical framework that resulted in the formulation and performance analysis of many possible management strategies or plans for Lake Ontario. The performance of each candidate Lake Ontario regulation plan was simulated with synthetic and climate change hydrological series and the different sets of outflows and levels that resulted were extensively analysed with specialised models of ecosystem response, shoreline erosion dynamics, and economics that described the trade off between benefits and losses associated with recreational boating, hydropower and commercial navigation. The modelling effort provided a better understanding of the performance of the regulation plans, as well as gains in knowledge of the effects 
of varying water levels on shoreline erosion, wetland plant communities and other elements of the ecosystem. For more detail, see [7].

Table 1: $\quad$ Lake Ontario quarter-monthly mean level statistics for the historic NBS case and selected stochastic centuries simulated with Plan 1958 D with deviations.

\begin{tabular}{|c|c|c|c|c|c|}
\hline & $\begin{array}{c}\text { Historic } \\
\text { case }\end{array}$ & C1 & C2 & C3 & C4 \\
\hline Average (m) & 74.74 & 74.59 & 74.78 & 74.76 & 74.49 \\
\hline Maximum (m) & 75.68 & 75.72 & 76.16 & 75.68 & 75.48 \\
\hline Minimum (m) & 73.78 & 73.04 & 73.52 & 74.06 & 73.26 \\
\hline
\end{tabular}

For the past several decades the outflows of Lake Ontario have been regulated by a Board of Control according to the rules set out in Plan 1958 D as well as their own discretionary judgement. A plan called "Plan 1958 D with deviations" was developed to simulate this present regulation regime with the different supply sequences described in the preceding sections. This plan was then used as the basis to compare the outcomes of the new candidate regulation plans. Table 1 from [5] summarizes some descriptive statistics of Lake Ontario simulated quarter-monthly levels using "Plan 1958 D with deviations" and the four selected 101-year long Lake Ontario net total supply series described in subsection 3.1 (C1, lowest 5-year moving average Lake Ontario supply; C2, highest 5-year moving average, which also had the largest range from wet to dry supplies; C3, a sequence with a similar range and average of supplies as the historical; and $\mathrm{C} 4$, the longest Lake Ontario drought). The simulation results for the longest synthetic Lake Ontario drought (C4), and the lowest 5-year moving average Lake Ontario supply (C1), show the lowest levels. Table 2 shows climate change scenarios statistics. The simulated levels with the Not as Warm and Wet scenario are close to the base case, while the Warm and Dry scenario simulated levels are the lowest.

Table 2: Lake Ontario quarter-monthly mean level statistics for the climate change scenarios simulated with Plan 1958 D with deviations.

\begin{tabular}{|c|c|c|c|c|c|}
\hline & $\begin{array}{c}\text { Base Case } \\
\mathbf{1 9 6 2 - 1 9 9 0}\end{array}$ & $\begin{array}{c}\text { Warm } \\
\text { and Dry }\end{array}$ & $\begin{array}{c}\text { Not as } \\
\text { Warm } \\
\text { and Dry }\end{array}$ & $\begin{array}{c}\text { Warm and } \\
\text { Wet }\end{array}$ & $\begin{array}{c}\text { Not as } \\
\text { Warm } \\
\text { and Wet }\end{array}$ \\
\hline Average (m) & 74.84 & 74.37 & 74.59 & 74.52 & 74.76 \\
\hline Maximum (m) & 75.53 & 75.06 & 75.24 & 75.39 & 75.54 \\
\hline Minimum (m) & 74.22 & 72.71 & 73.35 & 73.01 & 74.08 \\
\hline
\end{tabular}




\section{Conclusion}

The LOSLR Study not only introduced a new planning development vision, but also a sophisticated hydrological analysis using synthetic flow samples and climate change affected series. The objective was to develop robust Lake Ontario management strategies that perform adequately under a wide range of conditions.

The formulation of a complete hydrological modeling strategy using adequate models was one of the major challenges in the study. The team of international experts that was organised developed an innovative approach to capture the variation in hydrological conditions that any regulation plan selected for Lake Ontario regulation may have to deal with in the coming decades. The major achievements in terms of innovation are as follows.

- The use all available tools to assess the observed changes in the mean of Great Lakes precipitation and NBS series;

- The application of the Contemporaneous mix of Shifting Mean SM model and CARMA to the Great Lakes - St Lawrence System coupled with multi-stage disaggregation strategies, for generating NBS and synthetic flows series for the overall system.

- The coordinated use of many hydrological rainfall-runoff models, lake models, routing models with appropriate management rules, to prepare climate change hydrological NBS and flows series.

- The development of effective statistical and graphical frameworks to compare different modeling strategies, and visualize temporal and spatial results in an organized way.

The work of the LOSLR Study was accomplished using an open, collaborative process with the participation from multi-disciplinary scientists, engineers, economists and non-expert members of the public that are concerned about Lake Ontario outflow regulation. The outflow regulation options presented in the final report to the International Joint Commission all offer an improvement in the overall economic and environmental benefits of Lake Ontario outflow regulation but differ in the distribution of those benefits to the different interests. The wide array of plausible hydrological conditions used to develop and evaluate these plans adds to the confidence that the decision-makers have that their selected plan will perform as expected.

\section{Acknowledgements}

The work described in this paper would not have been completed without the participation, support and guidance of many specialists. In particular, deep gratitude is extended to Dr. Oli Sveinsson, for his tireless support with the stochastic modeling software. It has been a privilege and opportunity to discuss stochastic models and modeling strategies with such insight. Also, acknowledgements go to Hydro-Québec colleagues R. Guay, D. Sparks, D. Tremblay and M. Latraverse for their collaboration and contributions. Heartfelt thanks go to T. McAuley, A. Carpentier, T. Sassi and Dr. Y. Fan. 


\section{References}

[1] Caldwell R., and Fay D., Lake Ontario Pre-project Outlet Hydraulic Relationship, Environment Canada, Cornwall, Ontario, 2002.

[2] Croley, Thomas E. II, Great Lakes Climate Change Hydrologic Impact Assessment IJC Lake Ontario - St. Lawrence River Regulation Study. NOAA Technical Memorandum GLERL-126 NOAA, Great Lakes Environmental Research Laboratory, Ann Arbor MI 48105, September 2003.

[3] Fagherazzi L., Guay R., Sparks D., Salas J. and Sveinsson O., Stochastic Modeling and Simulation of the Great Lakes - St. Lawrence River system. Report prepared for the Lake Ontario-St. Lawrence River study of the International Joint Commission, Ottawa and Washington, 2005.

[4] Fagherazzi L., Guay R., Sassi T., Climate Change Analysis of the Ottawa River system. Report prepared for the Lake Ontario-St. Lawrence River study of the International Joint Commission, Ottawa and Washington, 2005.

[5] Fay D. and Fan Y., Hydrologic scenarios for the evaluation of Lake Ontario outflow Regulation Plans, paper presented to the CWRA Conference, Toronto, 2006.

[6] Fan Y. and Fay D., Final report on the development of empirical relationships to estimate water levels of the St Lawrence River from Montreal to Trois Rivieres, Report prepared for the Lake Ontario-St. Lawrence River Study of the International Joint Commission, Ottawa and Washington, 2002.

[7] International Joint Commission, Options for managing Lake Ontario and St. Lawrence River Water Levels and flows, Final Report by the International Lake Ontario - St. Lawrence River Study Board, March 2006.

[8] Mortsch, L., Alden M., Klaassen J., Development of Climate Change Scenarios for Impact and Adaptation Studies in the Great Lakes - St. Lawrence Basin. A Report prepared for the Hydrologic and Hydraulic Modeling Technical Working Group, International Lake Ontario - St. Lawrence River Study Board, International Joint Commission, Toronto, ON. (Adaptation and Impacts Research Group, Meteorological Service of Canada), 2005.

[9] Ripple Effects, Public Information Advisory group (PIAG) of the International Lake Ontario - St Lawrence River Study Board, July 2001

[10] Salas, J.D., Saada, N., Chung, C.H., Lane, W.L. and Frevert, D.K., Stochastic Analysis, Modeling and Simulation (SAMS) Version 2000 User's Manual, Colorado State University, Water Resources Hydrologic and Environmental Sciences, Technical Report Number 10, Engineering and Research Center, Colorado State University, Fort Collins, Colorado. 2000 .

[11] Sveinsson O., Salas J., Stochastic Modeling And Simulation Of The Great Lakes NBS Based On Univariate And Multivariate Shifting Mean - Dept. 
of Civil Engineering, Colorado State University, Fort Collins, January 2002.

[12] Sveinsson, O., and Salas, J.D., Multivariate Shifting Mean Plus Persistence Model for Simulating the Great Lakes Net Basin Supplies, Submitted to a Journal. 